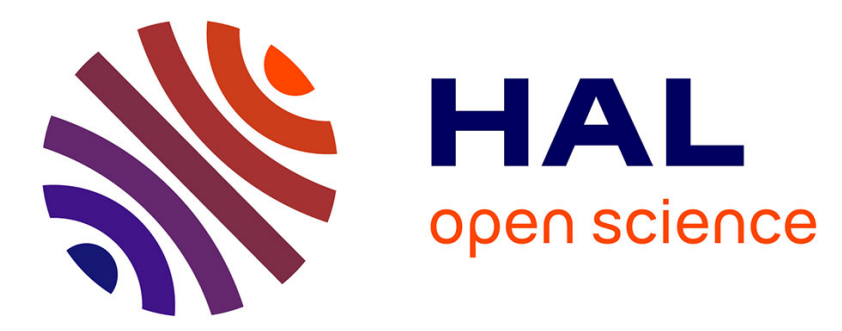

\title{
Characterization of the atmospheric temperature and moisture conditions above Dome C (Antarctica) during austral summer and fall months
}

C. Tomasi, B. Petkov, E. Benedetti, V. Vitale, A. Pellegrini, G. Dargaud, L. de Silvestri, P. Grigioni, E. Fossat, W. Roth, et al.

\section{To cite this version:}

C. Tomasi, B. Petkov, E. Benedetti, V. Vitale, A. Pellegrini, et al.. Characterization of the atmospheric temperature and moisture conditions above Dome C (Antarctica) during austral summer and fall months. Journal of Geophysical Research: Atmospheres, 2006, 111. hal-00417006

\section{HAL Id: hal-00417006 \\ https://hal.science/hal-00417006}

Submitted on 3 May 2021

HAL is a multi-disciplinary open access archive for the deposit and dissemination of scientific research documents, whether they are published or not. The documents may come from teaching and research institutions in France or abroad, or from public or private research centers.
L'archive ouverte pluridisciplinaire HAL, est destinée au dépôt et à la diffusion de documents scientifiques de niveau recherche, publiés ou non, émanant des établissements d'enseignement et de recherche français ou étrangers, des laboratoires publics ou privés. 


\title{
Characterization of the atmospheric temperature and moisture conditions above Dome $C$ (Antarctica) during austral summer and fall months
}

\author{
Claudio Tomasi, ${ }^{1}$ Boyan Petkov, ${ }^{1}$ Elena Benedetti, ${ }^{1}$ Vito Vitale, ${ }^{1}$ Andrea Pellegrini, ${ }^{2}$ \\ Guillaume Dargaud, ${ }^{2}$ Lorenzo De Silvestri, ${ }^{3}$ Paolo Grigioni, ${ }^{3}$ Eric Fossat, ${ }^{4}$ \\ William L. Roth, ${ }^{5}$ and Luca Valenziano ${ }^{6}$ \\ Received 12 December 2005; revised 8 June 2006; accepted 23 June 2006; published 21 October 2006.
}

[1] Two sets of radiosounding measurements were taken at Dome $\mathrm{C}$ (Antarctica) in December 2003 and January 2003 and 2004, using RS80-A, RS80-H, and RS90 Vaisala radiosondes, and from March to May 2005, employing the RS92 model. They were examined following accurate correction procedures to remove the main relative humidity dry bias and the temperature and humidity lag errors. The results showed that a strong cooling usually characterizes the thermal conditions of the whole troposphere from December/January to April/May, with an average temperature decrease from 245 to $220 \mathrm{~K}$ at the ground, of around $10 \mathrm{~K}$ at upper tropospheric levels, and of more than $15 \mathrm{~K}$ in the lower stratosphere. The relative humidity data were found to be affected by dry bias of $5-10 \%$, on average, for the RS80-A and RS80-H Humicap sensors and by smaller percentages for the other sensors. The mean monthly vertical profiles of absolute humidity were found to decrease sharply throughout the troposphere, especially within the first $3 \mathrm{~km}$, and to diminish considerably passing from December/January to March/April/ May, with average values of precipitable water decreasing from 0.75 to $0.28 \mathrm{~mm}$, median values from 0.69 to $0.25 \mathrm{~mm}$, and first and third quartiles from 0.60 to $0.22 \mathrm{~mm}$ and from 0.87 to $0.34 \mathrm{~mm}$, respectively. The results demonstrate that Dome C (where a permanent scientific station has been open for winter operations since austral winter 2005) is a site of comparable quality to the South Pole for both validation of satellite radiance measurements and astronomic observations in the infrared, submillimetric, and millimetric wavelength range, performed with large telescopes that cannot be carried on satellites.

Citation: Tomasi, C., et al. (2006), Characterization of the atmospheric temperature and moisture conditions above Dome C (Antarctica) during austral summer and fall months, J. Geophys. Res., 111, D20305, doi:10.1029/2005JD006976.

\section{Introduction}

[2] High-altitude sites in Antarctica are particularly suitable for submillimeter and millimeter astronomy studies, thanks to the extremely cold and dry air conditions of the atmosphere throughout the year, associated with very low vertical atmospheric contents of water vapor, generally smaller than $1 \mathrm{~mm}$ [Lane, 1998]. Together with the rela-

\footnotetext{
${ }^{1}$ Institute of Atmospheric Sciences and Climate, Consiglio Nazionale delle Ricerche, Bologna, Italy.

${ }^{2}$ Antarctic Project, Centro Ricerche Casaccia, Ente per le Nuove Tecnologie, l'Energia e l'Ambiente, Santa Maria di Galeria, Rome, Italy.

${ }^{3}$ Climate Section, Centro Ricerche Casaccia, Ente per le Nuove Tecnologie, l'Energia e l'Ambiente, Santa Maria di Galeria, Rome, Italy.

${ }^{4}$ Laboratoire d'Astrophysique, Université de Nice Sophia-Antipolis, Nice, France.

${ }^{5}$ Department of Geography, University of Idaho, Moscow, Idaho, USA.

${ }^{6}$ Institute of Space Astrophysics and Cosmic Physics, National Institute for Astrophysics, Bologna, Italy.
}

Copyright 2006 by the American Geophysical Union. 0148-0227/06/2005JD006976 tively low wind speed conditions frequently observed within the atmospheric boundary layer above these locations, the low-moisture characteristics of the troposphere constitute an important meteorological requirement for carrying out astronomic observations of good quality at wavelengths longer than the visible ones [Calisse et al., 2004]. In fact, water vapor is the dominant source of atmospheric opacity at infrared, millimetric and submillimetric wavelengths for standard atmosphere conditions, with absorption features closely depending on atmospheric temperature, pressure and humidity conditions that vary considerably with latitude and season. Even at the relatively low values of its columnar content observed in the remote regions of the Earth, water vapour contributes efficiently to the incoming radiation absorption, together with thousands of molecular lines due to other minor atmospheric gases [Waters, 1976; Bally, 1989].

[3] Long-term site testing measurements were carried out at the South Pole station $\left(89^{\circ} 59^{\prime} \mathrm{S}, 24^{\circ} 48^{\prime} \mathrm{W}, 2180 \mathrm{~m} \mathrm{MSL}\right)$. They showed that good submillimeter and millimeter astro- 
nomic measurements can be performed at this site [Burton et al., 1994; Lane, 1998; Bussmann et al., 2005], on account of low-temperature characteristics, low water vapor content in the atmospheric column and small fluctuations in millimeter wavelength brightness. Since Italian and French Antarctic programs have led to the construction of a station at Dome $\mathrm{C}\left(75^{\circ} 06^{\prime} \mathrm{S}, 123^{\circ} 21^{\prime} \mathrm{E}, 3250 \mathrm{~m} \mathrm{MSL}\right)$, which is open not only during a few austral summer months but also during wintertime, site testing measurements were also performed more recently at this site in order to evaluate its suitability for astrophysical observations [Valenziano et al., 1998; Valenziano and Dall'Oglio, 1999; Calisse et al., 2004; Lawrence et al., 2004; Aristidi et al., 2003, 2005]. Different measurement techniques were employed to perform the tests, involving a great variety of instruments: multiwavelength Sun photometers, infrared radiometers, radiosondes, multiaperture scintillation sensors (MASS), Sonic Detection and Ranging (SODAR) instruments and differential image motion monitors (DIMM). The results confirmed that exceptional astronomic observational conditions frequently occur above the Dome $\mathrm{C}$ site, favored by low-temperature conditions, limited wind speed near the ground, low atmospheric turbulence and small values of precipitable water, which were only seldom found to exceed $1 \mathrm{~mm}$ throughout the year. The good quality of the astronomical seeing conditions above Dome $\mathrm{C}$ was confirmed by the measurements carried out by Lawrence et al. [2004], who stated that Dome $\mathrm{C}$ had the requisites to become a new astronomy observatory where an interferometer could work on projects that would otherwise require a space mission.

[4] The above findings indicate the importance of carrying out more extensive measurements of the moisture, temperature and pressure parameters of the atmosphere above Dome $\mathrm{C}$, employing new radiosounding measurements throughout the whole year, to provide more exhaustive and complete data defining the atmospheric transparency conditions, not only for astrophysical and astronomical applications but also for climate studies. In fact, atmospheric water vapor is known to be the most dominant greenhouse gas in the Earth's atmosphere [Marsden and Valero, 2004], exerting a strong influence on the radiation balance of the surface-atmosphere system, due to its intense absorption of short-wave (solar) and long-wave (terrestrial) radiation [Yamanouchi and Charlok, 1995]. The former process is caused by the numerous absorption bands distributed throughout the $0.6 \div 3.7 \mu$ m wavelength range of the solar spectrum [Kondratyev, 1969; Leckner, 1978], whereas the latter takes place substantially through two distinct absorption mechanisms: (1) selective absorption, mainly produced by the vibrorotational band centered at $6.25 \mu \mathrm{m}$ wavelength and the rotational bands beyond $16 \mu \mathrm{m}$ [Goody, 1964], and (2) continuum absorption, induced by both foreign and self-broadening mechanisms of the lines belonging to the absorption bands of water vapor and its dimer molecules in the middle and far infrared [Bignell, 1970; Clough et al., 1989].

[5] Considering the usefulness of characterizing the temperature and moisture conditions of the atmosphere above Dome $\mathrm{C}$ during diverse periods of the year, it was decided to analyze the radiosounding data currently available at this site. They comprise two data sets carried out in different months by two research groups currently working at this
Antarctic station: (1) a first data set provided by the group of the University of Nice (France) and consisting of 101 radiosoundings taken in January 2003, December 2003, and January 2004 [Aristidi et al., 2005] and (2) a second data set consisting of 37 radiosoundings only, taken by the meteorological group of the Antarctic Project (ENEA, C. R. Casaccia, Rome) during March, April and May 2005. The activity of the latter group started in 2005 with the purpose of providing continuity to the radiosounding facility, thus satisfying the SCAR recommendation SCAR XXVII-12 for the provision of "upper air data on the Antarctic Plateau, in order to both improve numerical atmospheric modeling and precipitable water estimates and test novel vertical profiling techniques, such as GPS and other remotely sensed profiling."

[6] The analysis of the above radiosounding data is described in the present paper, which reports the mean monthly results describing the evolutionary patterns of atmospheric temperature and moisture conditions above Dome C.

\section{Analysis of the Radiosounding Data}

[7] The first data set was taken by the above mentioned French group. It included 34 radiosoundings made in December 2003 and 67 radiosoundings in January of 2003 and 2004. They were performed employing three different Vaisala radiosondes, the RS80-A, RS80-H and RS90 models, which are equipped with Barocap capacitive aneroid, Thermocap sensor, and Humicap sensor for measuring the total air pressure $p$ (in $\mathrm{hPa}$ ), air temperature $T$ (in ${ }^{\circ} \mathrm{C}$ ), and relative humidity $(\mathrm{RH}$, in $\%)$ with respect to liquid water, respectively, at all the numerous levels given by the radiosondes through the troposphere and the lower stratosphere. The Humicap sensors were manufactured using different polymers (A-type on the RS80-A model, H-type on the RS80-H model and a new H-type on the RS90 model). Therefore they present diverse response characteristics, providing data which need to be analyzed following different procedures.

[8] The second data set was taken by the Italian ENEA group, including an overall number of 37 radiosoundings, among which 4 were taken in March 2005, 16 in April 2005 and 17 in May 2005, all using Vaisala radiosondes, model RS92, equipped with new sensors (Barocap silicon, F-Thermocap and H-Humicap).

[9] The measurement range of the Barocap sensors mounted on the four Vaisala sondes entirely covers the one observed at Dome C (usually from a surface level value of around $645 \mathrm{hPa}$ up to $3 \mathrm{hPa}$ ), all the Vaisala specifications on the measurement accuracy being very similar for the four sensor models. The main characteristics of the Thermocap and Humicap sensors mounted on the four radiosonde models are given in Table 1, according to the specifications available in the Vaisala literature. In particular, it is worth noticing that the $63.2 \%$ response time (time constant) of the RS92 Thermocap sensor was evaluated by the manufacturer to be of less than $0.4 \mathrm{~s}$ at $p=1000 \mathrm{hPa}$, less than $1 \mathrm{~s}$ at $p=$ $100 \mathrm{hPa}$, and less than $2.5 \mathrm{~s}$ at $p=10 \mathrm{hPa}$, for flow velocity of $6 \mathrm{~m} \mathrm{~s}^{-1}$. The time constants of the Humicap sensors were evaluated by Miloshevich et al. [2004] (hereinafter referred to as M04) to increase almost exponentially as temperature $T$ decreases and to decrease to a moderate extent with decreas- 
Table 1. Characteristics of the Thermocap and Humicap Sensors Mounted on the Four Models of Vaisala Radiosondes Used to Carry Out the Radiosounding Data at Dome C, as Given by the Manufacturer or Drawn From the Literature

\begin{tabular}{|c|c|c|c|c|}
\hline \multirow[b]{2}{*}{ Characteristics } & \multicolumn{4}{|c|}{ Vaisala Radiosonde Model } \\
\hline & RS80-A & RS80-H & RS90 & RS92 \\
\hline \multicolumn{5}{|c|}{ Thermocap Sensor } \\
\hline Measurement range & $333-183 \mathrm{~K}$ & $333-183 \mathrm{~K}$ & $333-183 \mathrm{~K}$ & $333-183 \mathrm{~K}$ \\
\hline Resolution & $0.1 \mathrm{~K}$ & $0.1 \mathrm{~K}$ & $0.1 \mathrm{~K}$ & $0.1 \mathrm{~K}$ \\
\hline $\begin{array}{l}\text { Total uncertainty in } \\
\text { sounding (accuracy) }\end{array}$ & $\pm 0.2 \mathrm{~K}$ & $\pm 0.5 \mathrm{~K}$ & $\pm 0.5 \mathrm{~K}$ & $\pm 0.5 \mathrm{~K}$ \\
\hline Repeatability in calibration & $0.2 \mathrm{~K}$ & $0.2 \mathrm{~K}$ & $0.15 \mathrm{~K}$ & $0.15 \mathrm{~K}$ \\
\hline \multirow[t]{3}{*}{ Reproducibility in sounding } & $0.2 \mathrm{~K}$ (from 1060 to $50 \mathrm{hPa}$ ) & $0.2 \mathrm{~K}$ (from 1060 to $50 \mathrm{hPa}$ ) & $0.2 \mathrm{~K}$ (from 1080 to $100 \mathrm{hPa}$ ) & $0.2 \mathrm{~K}$ (from 1080 to $100 \mathrm{hPa}$ ) \\
\hline & $0.3 \mathrm{~K}$ (from 50 to $15 \mathrm{hPa}$ ) & $0.3 \mathrm{~K}$ (from 50 to $15 \mathrm{hPa}$ ) & $0.3 \mathrm{~K}$ (from 100 to $20 \mathrm{hPa}$ ) & $0.3 \mathrm{~K}$ (from 100 to $20 \mathrm{hPa}$ ) \\
\hline & $0.4 \mathrm{~K}$ (from 15 to $3 \mathrm{hPa}$ ) & $0.4 \mathrm{~K}$ (from 15 to $3 \mathrm{hPa}$ ) & $0.5 \mathrm{~K}$ (from 20 to $3 \mathrm{hPa}$ ) & $0.5 \mathrm{~K}$ (from 20 to $3 \mathrm{hPa}$ ) \\
\hline Measurement range & $2-100 \%$ RH & $0-100 \%$ RH & $0-100 \%$ RH & $0-100 \% \mathrm{RH}$ \\
\hline Resolution & $1 \% \mathrm{RH}$ & $1 \% \mathrm{RH}$ & $1 \% \mathrm{RH}$ & $1 \% \mathrm{RH}$ \\
\hline $\begin{array}{l}\text { Total uncertainty in } \\
\text { sounding (accuracy) }\end{array}$ & $< \pm 3 \% \mathrm{RH}$ & $\pm 5 \% \mathrm{RH}$ & $\pm 5 \% \mathrm{RH}$ & $\pm 5 \% \mathrm{RH}$ \\
\hline Repeatability in calibration & $2 \% \mathrm{RH}$ & $2 \% \mathrm{RH}$ & $2 \% \mathrm{RH}$ & $2 \% \mathrm{RH}$ \\
\hline Reproducibility in sounding & $<3 \% \mathrm{RH}$ & $<3 \% \mathrm{RH}$ & $<3 \% \mathrm{RH}$ & $2 \% \mathrm{RH}$ \\
\hline
\end{tabular}

ing $p$, also depending on the negative or positive trend of relative humidity $\mathrm{RH}$ with height. Reliable evaluations of the time constant for different values of $T$ ranging between $25^{\circ} \mathrm{C}$ and $-60^{\circ} \mathrm{C}$ can be found in the M04 Table 1, for the RS80-A, RS80-H and RS90 radiosondes. The time constant of the RS92 Humicap sensor was estimated to assume similar values to those of the RS90 model throughout the entire range $\mathrm{T}>-60^{\circ} \mathrm{C}$ [Miloshevich et al., 2006] (hereinafter referred to as M06).

[10] Each radiosounding measurement provided the values of the various thermodynamic parameters at all the standard, mandatory significant and additional levels. In general, more than 600 measurement levels were found in the troposphere, usually taken every a few meters one from the next, and more than 1700 were found in the stratosphere, from the tropopause level up to the radiosonde top level, mostly ranging between 18 and $26 \mathrm{~km}$. The thermodynamic parameters given directly by the radiosondes were the following: (1) time $\tau$ after the launch, measured with the precision of $1 \mathrm{~s},(2)$ geometrical altitude $Z$ (in $\mathrm{m}$ ), (3) pressure $p$ (in $\mathrm{hPa}$ ), (4) air temperature $T$ (in ${ }^{\circ} \mathrm{C}$ ), and (5) relative humidity $\mathrm{RH}$ (in $\%)$. The ascent rate $v$ of the radiosonde $\left(\mathrm{m} \mathrm{s}^{-1}\right)$ was subsequently calculated from the sequence of pairs of values of $\tau$ and $Z$ determined at each measurement level.

[11] The values of air pressure $p$ given by the various Barocap sensors within the ground layer of about $200 \mathrm{~m}$ depth were first analyzed separately for each radiosounding by applying an exponential extrapolation procedure in height, in order to determine the surface level value $p_{o}$ relative to each radiosounding. Then, all the vertical profiles of $p$ were analyzed through exponential interpolation between the values given by the radiosondes at their measurement levels, to define the values of air pressure at the fixed levels, selected from the first level close to the ground up to $25 \mathrm{~km}$, in steps of $25 \mathrm{~m}$ up to $4 \mathrm{~km}, 50 \mathrm{~m}$ from 4 to $5 \mathrm{~km}, 100 \mathrm{~m}$ from 5 to $12 \mathrm{~km}$, and $250 \mathrm{~m}$ from 12 to $25 \mathrm{~km}$. These values of $p$ were subsequently subdivided into five monthly subsets relative to December, January, March, April and May, for which the average monthly values of $p$ were determined at all the fixed levels, together with their standard deviations. The above procedure provided the following mean monthly values of the surface level pressure: $p_{o}=658.0 \pm 5.1 \mathrm{hPa}$ in December, $p_{o}=650.7 \pm 3.6 \mathrm{hPa}$ in January, $p_{o}=640.1 \pm 1.6 \mathrm{hPa}$ in March, $p_{o}=635.1 \pm 5.2 \mathrm{hPa}$ in April, and $p_{o}=641.0 \pm 6.7 \mathrm{hPa}$ in May. These results agree satisfactorily with the yearly median value of $644 \mathrm{hPa}$ found by Valenziano and Dall'Oglio [1999] at Dome C, examining the Automatic Weather Station (AWS) meteorological data recorded from 1986 to 1993.

[12] The temperature data given by the radiosondes are originally affected by errors due to heat exchange effects produced by different causes, such as the solar and/or infrared irradiation of the Thermocap sensor, heat conduction to the sensor from its attachment points, and radiation emitted by the sensor. The corresponding corrections were made using the Vaisala standard correction procedure, yielding very similar correction terms to those obtained with the procedure proposed by Luers and Eskridge [1995]. Besides these environmental errors, it was also taken into account that the temperature data are usually affected by lag errors, mainly due to air pressure changes and ventilation speed, which need to be removed considering the different manufacturing characteristics of the Thermocap sensors.

[13] 1. Both RS80-A and RS80-H data were corrected using an algorithm obtained by Tomasi et al. [2004] as the best fit curve of the measurements of lag coefficient $\alpha_{T}$ performed by Huovila and Tuominen [1991] within the decreasing range of $p$ from 1000 to $10 \mathrm{hPa}$, in the following form:

$$
\alpha_{T}=35.15 p^{-0.3877},
$$

where $\alpha_{T}$ is measured in $\mathrm{s}$ and $p$ in $\mathrm{hPa}$. Using this correction algorithm for the values of the radiosonde balloon ascent rate $v$ calculated above (found to vary mostly between 5 and $6 \mathrm{~m} \mathrm{~s}^{-1}$ ), the temperature correction suitable for removing the corresponding lag effect was evaluated at each measurement level.

[14] 2. The lag errors affecting the temperature data of the RS90 and RS92 radiosondes were neglected according to the Luers [1997] results, since these errors were estimated to be associated with low values of the thermometer lag coefficients. In fact, calculations made on the basis of the Thermocap characteristics indicate that the lag coefficient should generally increase from $0.48 \mathrm{~s}$ at the Dome $\mathrm{C}$ surface 
level to no more than $1.70 \mathrm{~s}$ at the $25 \mathrm{~km} \mathrm{level}$ (corresponding to $\sim 26 \mathrm{hPa}$ ).

[15] The RH data provided by the Humicap sensors mounted on the four Vaisala radiosondes employed at Dome $\mathrm{C}$ were originally affected by important errors, as pointed out by Wang et al. [2002] (hereinafter referred to as W02), due to temperature dependence (TD), chemical contamination (CC), basic calibration model (BCM), sensor aging (SA), ground check (GC), and sensor arm heating (SAH). The first four of the errors were estimated by W02 to predominate on the others. In fact, the GC errors were estimated to be in general appreciably lower than $1 \%$, on the average. With regard to the $\mathrm{SAH}$ errors, they were not corrected here since very little is known about them and the correction procedures currently available are suspected to cause some additional errors rather than remove the original ones (W02).

[16] Moreover, M04 found more recently that the RH data are affected by lag errors which can be corrected in a satisfactory way by following the M04 procedure. Therefore we examined all the RH data given by the above four Humicap sensor models (1) following the W02 procedures to calculate the dry bias arising from different physical and chemical processes and (2) combining them with the overall M04 procedure, which was specifically designed to correct the lag errors and smooth the RH profiles through appropriate specific steps. On this basis, the $\mathrm{RH}$ data were analyzed as follows.

[17] 1. Examining the recent accuracy estimates of the Vaisala Humicap sensors determined by M06 in the middle and upper troposphere, the mean accuracy relative to $\mathrm{RH}=$ $2 \%$ was found to be equal on the average to $1.5 \%$ in the middle troposphere and $2.5 \%$ in the upper troposphere. On the basis of these evaluations, we discarded all the original values of $\mathrm{RH} \leq 2 \%$ given by the four Vaisala radiosonde models employed at Dome C. This selection criterion prompted us to reject most of the RH values measured at levels higher than $10 \mathrm{~km}$ (which are mainly equal to $1 \%$ and therefore comparable to the instrumental resolution) and a relatively very small number of RH values at tropospheric levels: actually, no more than $100 \mathrm{RH}$ tropospheric values were discarded, against the overall number of more than $80,000 \mathrm{RH}$ values measured throughout the troposphere.

[18] 2. The remaining data were then examined following the preliminary M04 procedure to construct a more schematic "skeleton" of the measured profiles. Bearing in mind that the original RH data are given by the radiosondes in steps of $1 \%$ resolution, the initial step of the M04 procedure allowed us to represent each altitude interval where $\mathrm{RH}$ assumed constant values by means of three points only, one in the center of the interval and two at the ends, thus making the subsequent smoothing steps envisaged by the M04 procedure easier and more accurate (see the further step 7 of the present correction procedure).

[19] 3. After this substitution, which is the first step of the more complex procedure adopted by M04 to correct the lag errors, the RH data were corrected for the BCM errors, by calculating them as follows: (1) those of the A-Humicap data provided by the RS80-A radiosondes, using the algorithm defined by the W02 equation (4.6-A), where the basic calibration RH was determined in terms of the W02 equation (5.1-A), and (2) those of the H-Humicap data given by the RS80-H radiosondes, using the correction factor given by the W02 equation $(4.6-\mathrm{H})$, where the basic calibration RH was evaluated in terms of the W02 equation (5.1-H). Conversely, the errors of the H-Humicap data given by the RS90 and RS92 radiosondes were neglected, according to M06.

[20] 4. No corrections were made for the CC errors of the RH data obtained at step 3 for the four radiosonde models since (1) the RS80-A, RS80-H and RS90 radiosondes were all manufactured after June 2000 and were therefore affected by errors of the RS 80 models that were evaluated by M04 to be so strongly reduced as to become negligible in all cases where "young age" sensors were employed and by errors affecting the RS90 data that were estimated to be even smaller thanks to the recent improvements of the polymer characteristics through "the replacement of Styrofoam in the radiosonde construction by cardboard," as pointed out by M04, and (2) the RS92 radiosondes were all properly heated and regenerated prior to launch, so that they provided data that did not require correction for errors of this kind, according to M04.

[21] 5. The TD corrections of these RH data were subsequently performed by (1) using the algorithms given by the W02 equations (4.4), (4.5), and (5.2-A) to correct the RS80-A data, since they are based on the set of calibration and temperature dependence measurements performed by Miloshevich et al. [2001], (2) using the calibration algorithm defined in terms of the W02 equation $(5.2-\mathrm{H})$ for all the RS80-H data, and (3) neglecting to correct the H-Humicap data given by the RS 90 and RS 92 radiosondes for the TD errors, as suggested by M06 for the radiosondes manufactured after 25 June 2001, as was the case of all the radiosondes employed in the present analysis.

[22] 6. The RH data obtained at step 5 were subsequently corrected for the SA errors, which were evaluated by (1) using the algorithm given by the W02 equation (4.11-A) for the RS80-A data to take into account that the A-Humicap sensor is in general unstable and drifts during storage, causing SA errors generally estimated to vary between $0.8 \%$ and $1.3 \%$ as the radiosonde age increases from 1 to 2 years, (2) using the algorithm defined by the W02 equation (4.11-H) for the RS80-H data to estimate the dry bias as a function of the sonde age, providing in our cases RH errors of no more than $2 \%$, and (3) avoiding to correct the H-Humicap data given by the RS90 and RS92 radiosondes, according to M06.

[23] 7. The RH data obtained above were subsequently corrected for the lag errors by following the M04 complex procedure, consisting of (1) a first smoothing procedure of the RH vertical profiles in order to minimize the "tiny changes in slopes at the skeleton points," which are amplified in proportion to the time constant, (2) the M04 lag correction procedure, based on the use of the M04 equation (1) for the exponent and coefficient values given in M04's Tables 2 and 3 , which allows the definition of the most suitable time constant values for the RS80-A, RS80-H, RS90 and RS92 radiosondes, and (3) a further smoothing procedure applied to the vertical profiles derived at points 1 and 2 in order to reduce the discontinuity features of the $\mathrm{RH}$ vertical profile.

[24] Some examples of vertical profiles of temperature and RH obtained through the above procedure are shown in Figures 1 and 2. Figure 1 shows the vertical profiles of 
TEMPERATURE $\left({ }^{\circ} \mathrm{C}\right)$

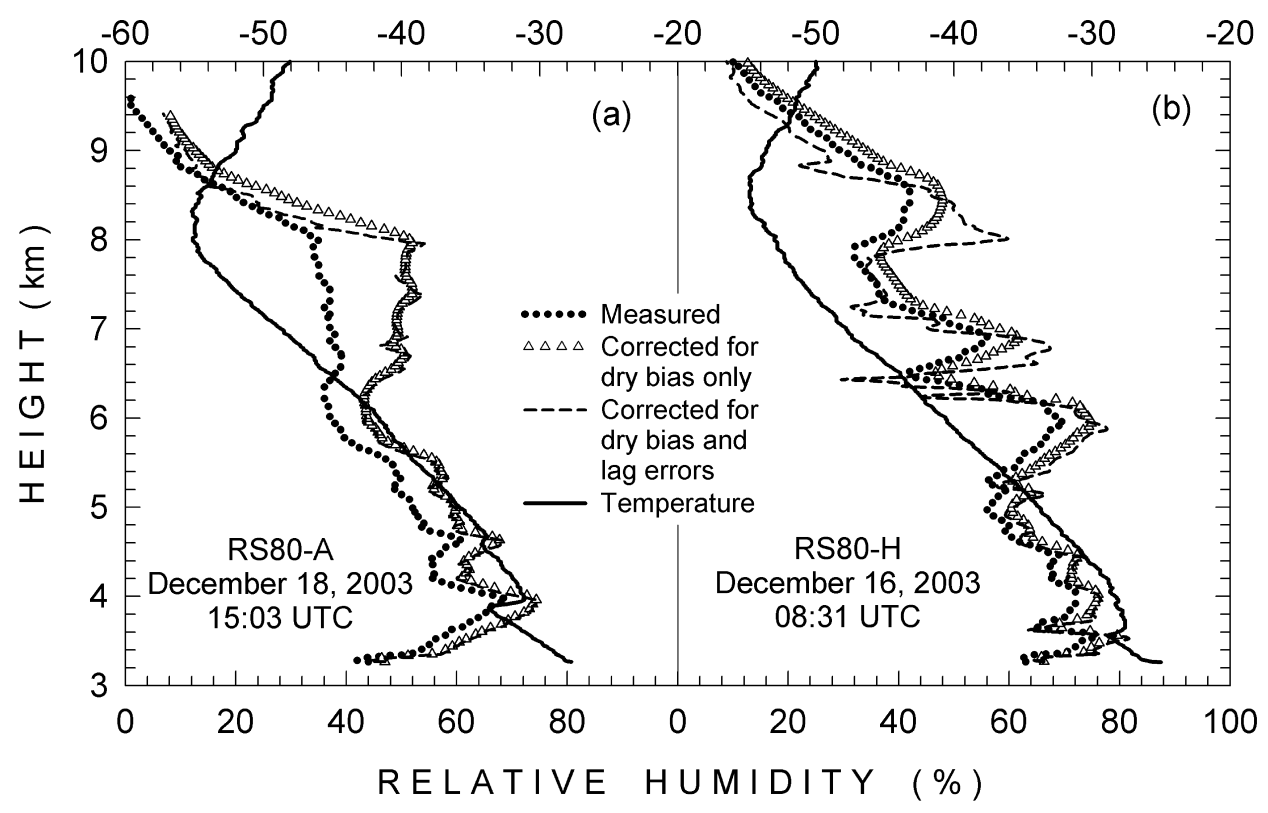

Figure 1. Vertical profiles of air temperature (solid curves) and relative humidity (RH) obtained from the radiosounding data taken on (left) 18 December 2003 (1503 UTC) using a RS80-A radiosonde and (right) 16 December 2003 (0831 UTC) using a RS80-H radiosonde. The original RH data provided by the radiosondes are given by small solid circles; the RH data corrected using the preliminary M04 smoothing procedure (through steps 1 and 2) and the W02 correction procedure for removing the dry bias of different type (through steps 3-6) are given by open triangles; the RH data obtained subsequently through step 7, following the M04 lag correction procedure and the second smoothing procedure, are given by the dashed curves.

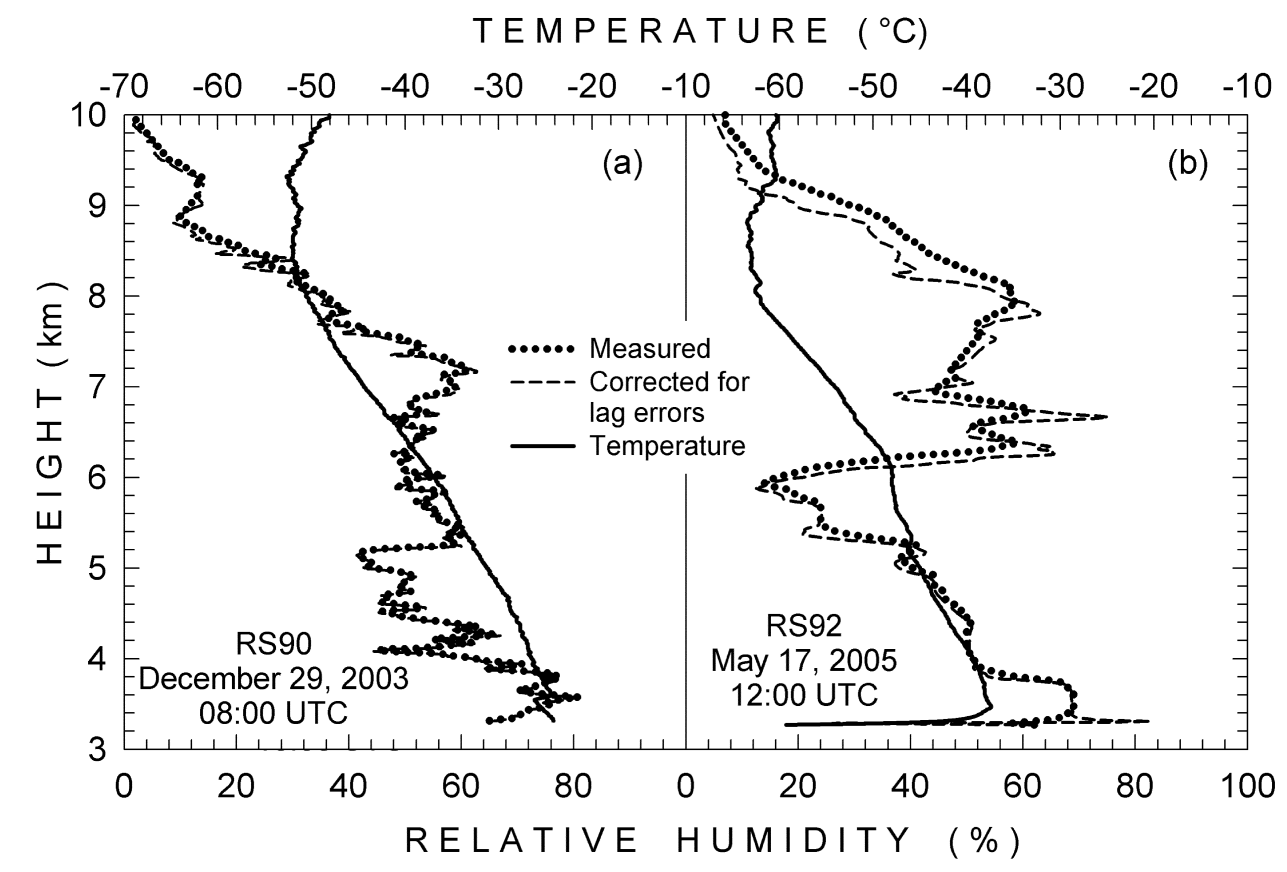

Figure 2. As in Figure 1 (a) on 29 December 2003 (0800 UTC) for the RS90 radiosounding data taken and (b) for the RS92 radiosounding data taken on 17 May 2005 (1200 UTC). Figures 2a and 2b show only the vertical profiles of the original RH data (small solid circles) and the time lag corrected and smoothed RH data, as obtained through steps 1, 2, and 7 (dashed curve) since both the RS90 and RS92 RH measurements do not need to be corrected for the dry bias. 
temperature relative to two radiosounding measurements, and the corresponding vertical curves of (1) RH values, as given by the original data, (2) $\mathrm{RH}$ values, obtained through the dry bias corrections only, and (3) the final RH values, determined through the use of the overall correction procedure described above, and hence including both dry bias and lag corrections. The first example refers to a radiosounding taken with the RS80-A model and the second with the RS80-H model. The first case shows very clearly that the RS80-A dry bias corrections are relatively low $(<10 \% \mathrm{RH})$ at all the lower tropospheric levels where the temperature is higher than $-40^{\circ} \mathrm{C}$, and result to increase at upper levels to more than $15 \% \mathrm{RH}$ when the temperature is lower than $-50^{\circ} \mathrm{C}$. Correspondingly, the lag corrections were found to become gradually more marked as the radiosonde approached the tropopause level, assuming values comparable with the magnitude of the bias at the levels where the humidity gradient is particularly high and the temperature is low, as pointed out by Leiterer et al. [2005]. Thus the results in Figure 1 agree very well with the mean estimates of the RS80-A dry bias obtained by Leiterer et al. [2005] through a comparison between traditional radiosonde data and results found employing the "new Lindenberg FN method of standardized frequencies". The second case shows that the RS80-H dry bias corrections are considerably smaller than those found in the previous case relative to the RS80-A radiosonde model. In fact, they are lower than $10 \%$ $\mathrm{RH}$ throughout the whole troposphere, for temperature values ranging between $-25^{\circ} \mathrm{C}$ and $-55^{\circ} \mathrm{C}$. On the contrary, the lag errors were found to be larger than those estimated in the first example, due to the longer time-constant values defined by M04 for the RS80-H Humicap sensor model.

[25] The first example in Figure 2 refers to a radiosounding taken with the RS90 radiosonde, and the second to the RS92 model. The vertical profiles of RH pertaining to the first case are very close to each other, confirming the occurrence of very small lag errors, actually not exceeding a few percentage points at all altitudes and for all the temperature conditions. The vertical profiles of RH shown in the second example refer only to (1) the original data and (2) the data obtained through the correction procedure for the lag errors, since the RH dry bias were assumed to be totally negligible for the RS92 data, according to M06. Conversely, the lag errors were found to be significant and to change in sign, requiring negative corrections in cases where RH decreases with altitude, and positive corrections for increasing trends of $\mathrm{RH}$ with altitude. At upper levels, close to the tropopause region, the lag corrections were found to be all of negative sign since the RH strongly decreased monotonically with height, when the radiosonde passed from the troposphere to the stratosphere. The comparison in Figure 2 shows also that the lag errors are less marked in the RS90 case than in the RS92 one. Such behavior is not due to the differences in the Humicap sensor characteristics but can be more reasonably ascribed to the different environment conditions: those of the RS90 case are associated with thermal conditions of the austral summer atmosphere, presenting temperature values decreasing slowly from $-25^{\circ} \mathrm{C}$ to $-52^{\circ} \mathrm{C}$ as the height increases from the surface up to the tropopause level, while those of the RS92 case are related to temperature values typical of austral fall conditions, equal to about $-60^{\circ} \mathrm{C}$ at the surface level, about $-40^{\circ} \mathrm{C}$ at the top level of the ground temperature inversion, and $-65^{\circ} \mathrm{C}$ close to the tropopause level.

\section{Mean Monthly Vertical Profiles of Temperature and Moisture Parameters}

[26] The results presented in Figures 1 and 2 give a clear measure of the wide variability of the overall correction term $\Delta \mathrm{RH}$ as a function of altitude, this parameter being given at each level by the sum of the Humicap dry bias and lag errors estimated following the W02 and M04 procedures described in section 2. In order to evaluate the weight of these corrections in modifying the original data, the values of parameter $\Delta \mathrm{RH}$ were calculated for each radiosounding, at each fixed level, $\Delta \mathrm{RH}$ being given by the difference between the final value of $\mathrm{RH}$ obtained through the whole correction procedure and the original one. The vertical profiles of $\Delta \mathrm{RH}$ were then subdivided into five monthly sets relative to each radiosonde model. For each set, the average monthly vertical profiles of $\Delta \mathrm{RH}$ were then calculated. Figure 3 presents the mean monthly vertical profiles of $\triangle \mathrm{RH}$ determined for the various radiosonde models in December, January, April and May, since the March data set was not considered because of its poor representativeness, due to the very low number of radiosoundings. Figure 3 shows that the values of $\triangle \mathrm{RH}$ found with the RS80-A sondes in December and January are appreciably higher than those derived from the RS80-H measurements carried out during the same months. Conversely, those relative to RS90 sondes are mostly of a few percent only, with relatively higher values at altitudes varying between 6 and $8 \mathrm{~km}$. The values of $\Delta \mathrm{RH}$ determined from the RS92 humidity data are of less importance than those found for the other data provided by the RS80-A, RS80-H and RS90 sensors, principally owing to the better performances of the RS92 Humicap sensor with respect to the RS80-A and RS80-H models. The differences among the mean vertical profiles of $\triangle \mathrm{RH}$ shown in Figure 3 for the months of December and January can be explained mainly in terms of the diverse performances of the Humicap sensors in the presence of different vertical distribution features of $\mathrm{RH}$ and humidity gradients.

[27] For each vertical profile of $T$ obtained from the various radiosounding monthly data sets, we calculated the values of $T$ at the first significant value given by the radiosonde (usually ranging between 3265 and $3270 \mathrm{~m}$ heights) and at another 172 fixed levels from $3275 \mathrm{~m}$ height to the $25 \mathrm{~km}$ level. This was carried out by following the linear interpolation procedure of $T$ in height, the fixed levels being taken in the same altitude steps adopted in section 2 for determining the vertical profiles of $p$ up to the $25 \mathrm{~km}$ level. All the data defining 138 vertical profiles of $T$ were then subdivided into five monthly sets, for which the average monthly values of $T$ were calculated at all the fixed levels together with the corresponding standard deviations. The vertical profiles thus obtained are shown in Figure 4. As can be seen, the tropospheric region is subject to a strong cooling, passing from the austral summer months (December and January) to the fall ones (March, April and May), by about $10 \mathrm{~K}$ on the average throughout the whole troposphere and by more than $25 \mathrm{~K}$ at the ground. The temperature minimum characterizing the tropopause region 


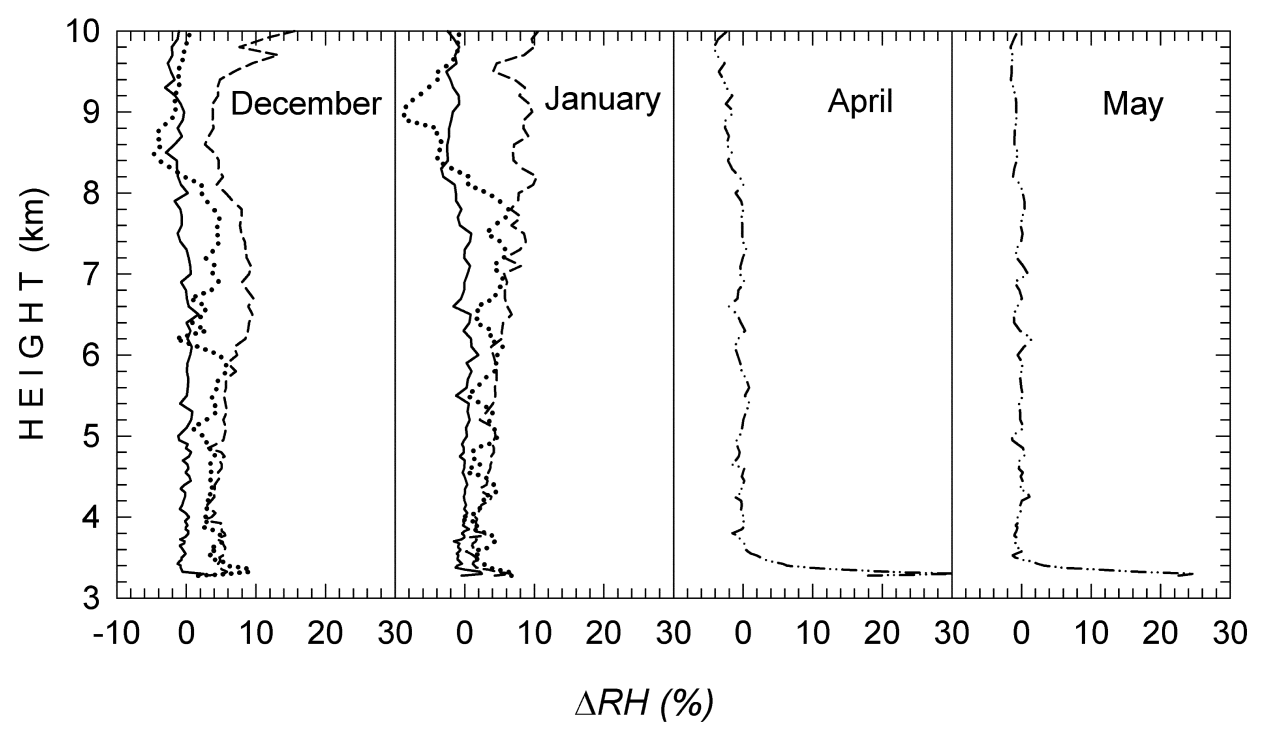

Figure 3. Mean monthly vertical profiles of parameter $\Delta \mathrm{RH}$ given at each level by the sum of the dry bias and lag errors determined following the W02 and M04 procedures adopted in section 2 for the monthly RH dats sets of December, January, April, and May. Dashed curves refer to the RS80-A data, dotted curves refer to the RS80-H data, solid curves refer to the RS90 data, and dashed-dotted curves refer to the RS92 data.

appears to become more pronounced in March and April, since the cooling processes affecting the lower part of the stratosphere are limited in these months within the narrow layer having depth of a few kilometers above the tropopause level. On the contrary, the cooling of the stratosphere is more marked in May, the temperature decreasing further by more than $10 \mathrm{~K}$ throughout the stratosphere, above $9 \mathrm{~km}$ height.

[28] Figure 4 also shows that the mean monthly temperature values at the surface level are around $245 \mathrm{~K}$ in December and January and around $220 \mathrm{~K}$ from March to May, these findings being in accordance with the results found by Valenziano and Dall'Oglio [1999] at Dome C over a 7-year data set of AWS meteorological data, from which average seasonal values of ground temperature equal to $-65^{\circ} \mathrm{C}(\sim 208 \mathrm{~K})$ in the austral winter and $-26^{\circ} \mathrm{C}(\sim 247 \mathrm{~K})$ in summer were found, with an annual median value of $-53^{\circ} \mathrm{C}(\sim 220 \mathrm{~K})$. Our results for surface temperature are therefore fully comparable with the findings of Valenziano and Dall'Oglio [1999] and those reported by Aristidi et al. [2005].

[29] The following procedure was adopted in order to obtain a common sequence of fixed altitude levels at which the moisture parameters available from the present radiosounding measurements can be correctly averaged to obtain more homogeneous results.

[30] 1. For each pair of $T$ and RH relative to each level of each radiosounding, the values of parameters $E(T)$ and $T_{d}$ were calculated with (1) saturation vapor pressure $E(T)$ in the pure phase over a plane surface of pure water, using the well-known Bolton [1980] formula, and (2) dew point $T_{d}$, using the inverse Bolton [1980] formula, where the water vapour partial pressure $e$ was determined as the product of $E(T)$ by RH.

[31] 2. For each pair of vertical profiles of $T$ and $T_{d}$, the values of the two parameters were then calculated at the surface and the other 172 fixed levels established above, through a linear interpolation procedure in height similar to that adopted by Tomasi et al. [2004].

[32] 3. For each pair of $T$ and $T_{d}$ calculated at one of the fixed levels, the other moisture parameters $\mathrm{RH}$, partial pressure $e$, and absolute humidity $q$, were determined by (1) calculating again $E(T)$ and $e=E\left(T_{d}\right)$ in terms of the Bolton [1980] formula, (2) determining $\mathrm{RH}$ as the ratio $E\left(T_{d}\right) / E(T)$, and (3) evaluating $q$ (measured in $\mathrm{g} \mathrm{m}^{-3}$ ) in terms of the well-known equation of state for water vapor, that is as the ratio of parameter $e$ (measured in $\mathrm{hPa}$ ) to the product $4.615 \times 10^{-3} T$ (with $T$ measured in $\mathrm{K}$ ).

[33] The overall set consisting of 138 vertical profiles of parameter $q$ was then subdivided into five monthly subsets to determine the mean monthly values of this parameter at the surface level and the other 172 fixed levels from 3.275 to $25 \mathrm{~km}$, together with the corresponding standard deviations. The results are shown in Figure 5, giving evidence of the marked variations in the moisture conditions of the troposphere taking place at all levels from the surface up to $8 \mathrm{~km}$ altitude, when passing from the December/January period to the austral fall months. These large changes indicate also that precipitable water is expected to assume values in the austral fall months that are considerably lower than those observed during the austral summer. In order to evaluate these seasonal variations, we calculated precipitable water $W$ for all the 138 vertical profiles of $q$ determined above, by integrating the absolute humidity from the surface level up to the top level measured by the Humicap sensor, and then adding the precipitable water contribution given by the atmospheric region between the Humicap sensor top level and the $10 \mathrm{~km}$ height, as calculated through integration of the mean monthly vertical profiles of $q$ presented in Figure 5 , in all cases where such a calculation needs to be completed. 


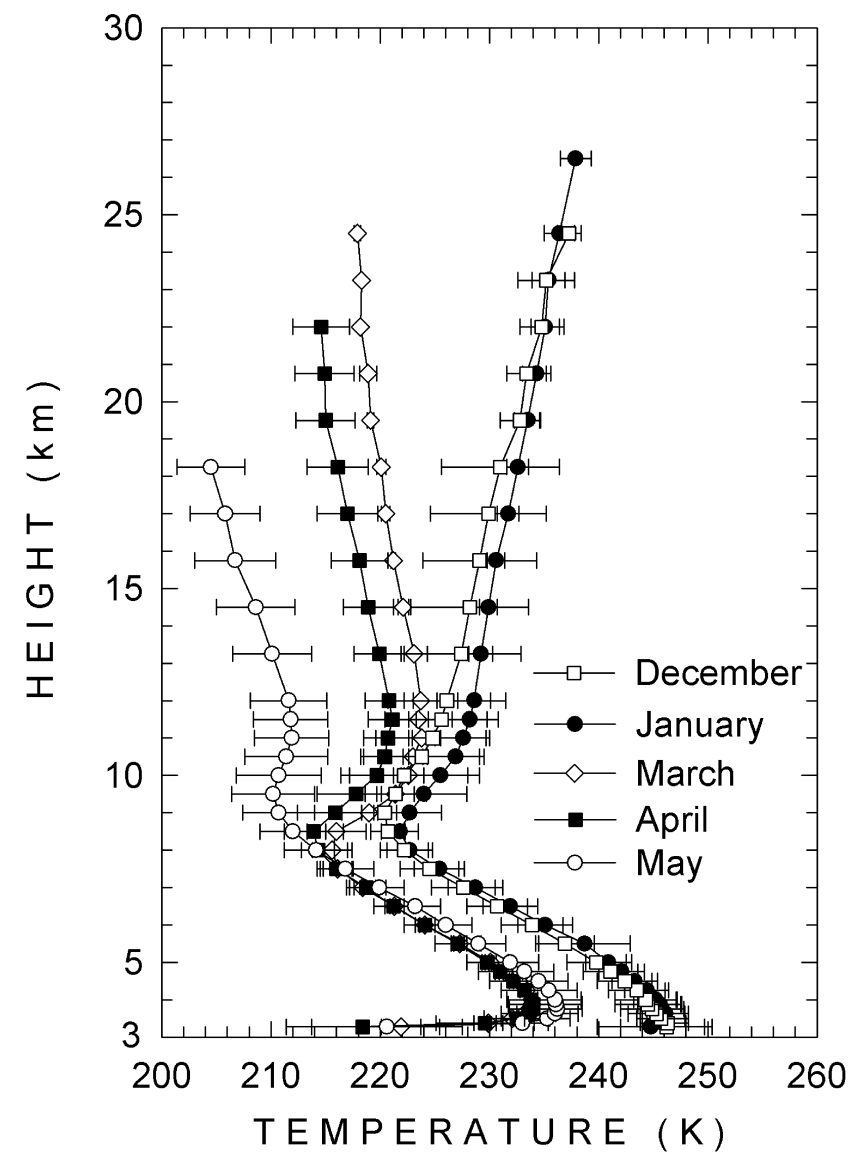

Figure 4. Mean monthly vertical profiles of air temperature $T(\mathrm{~K})$ obtained from the monthly data sets relative to December (open squares), January (solid circles), March (open diamonds), April (solid squares), and May (open circles). The bars represent the standard deviations obtained at some fixed levels, giving a measure of the dispersion of the monthly data.

[34] Bearing in mind the results obtained by Turner et al. [2003] and M06, the above evaluations of $W$ were corrected for the solar heating errors of the H-Humicap sensors. In fact, through thousands of comparison tests performed in northern Oklahoma from 1994 to 2000, Turner et al. [2003] found that dry bias affects the daytime measurements of precipitable water derived from RS80-H Humicap data by $3-4 \%$ on average. Examining a set of RS90 radiosonde measurements performed in October and November 2003, M06 estimated that the daytime dry bias of $W$ varied between $6 \%$ and $8 \%$ on average. Thus we took into account that the incoming density flux of global solar radiation at Dome $\mathrm{C}$ can vary appreciably as a function of solar zenith angle (SZA), mostly assuming considerably lower values than those observed at the midlatitude sites of the Northern Hemisphere, corresponding to generally smaller values of SZA throughout the day. The solar heating error was evaluated for each radiosounding by calculating the incoming solar irradiance in the Dome $\mathrm{C}$ atmosphere and normalizing it to the midlatitude value calculated in the standard atmosphere for the average value of $\mathrm{SZA}=55^{\circ}$. Multiplying this solar irradiance ratio determined for each Dome C radiosounding by (1) the average correction factor proposed by Turner et al. [2003] as equal to 1.035 for the RS 80 radiosonde measurements or (2) the M06 average correction factor equal to 1.07 for the RS90 radiosondes, it was found that the solar heating dry bias varied between $0.8 \%$ and $3.7 \%$ for the RS 80 evaluations of $W$ and between $1.3 \%$ and $6.9 \%$ for the RS90 ones. Solar heating dry bias was not corrected for the RS92 results since only nighttime radiosoundings were performed from late March to late May.

[35] The values of $W$ determined above were corrected for this kind of dry bias using a specific correction term for each radiosounding and then subdivided into four monthly subsets, relative to the December, January, late March/April (hence including also the 4 days from 25 to $30 \mathrm{March}$ ), and May periods, respectively. For these subsets, the following mean monthly values were obtained together with the corresponding standard deviations: $W=0.73 \pm 0.20 \mathrm{~mm}$ in December, $W=0.78 \pm 0.19 \mathrm{~mm}$ in January, $W=0.26 \pm$ $0.08 \mathrm{~mm}$ in March/April, and $W=0.30 \pm 0.10 \mathrm{~mm}$ in May.

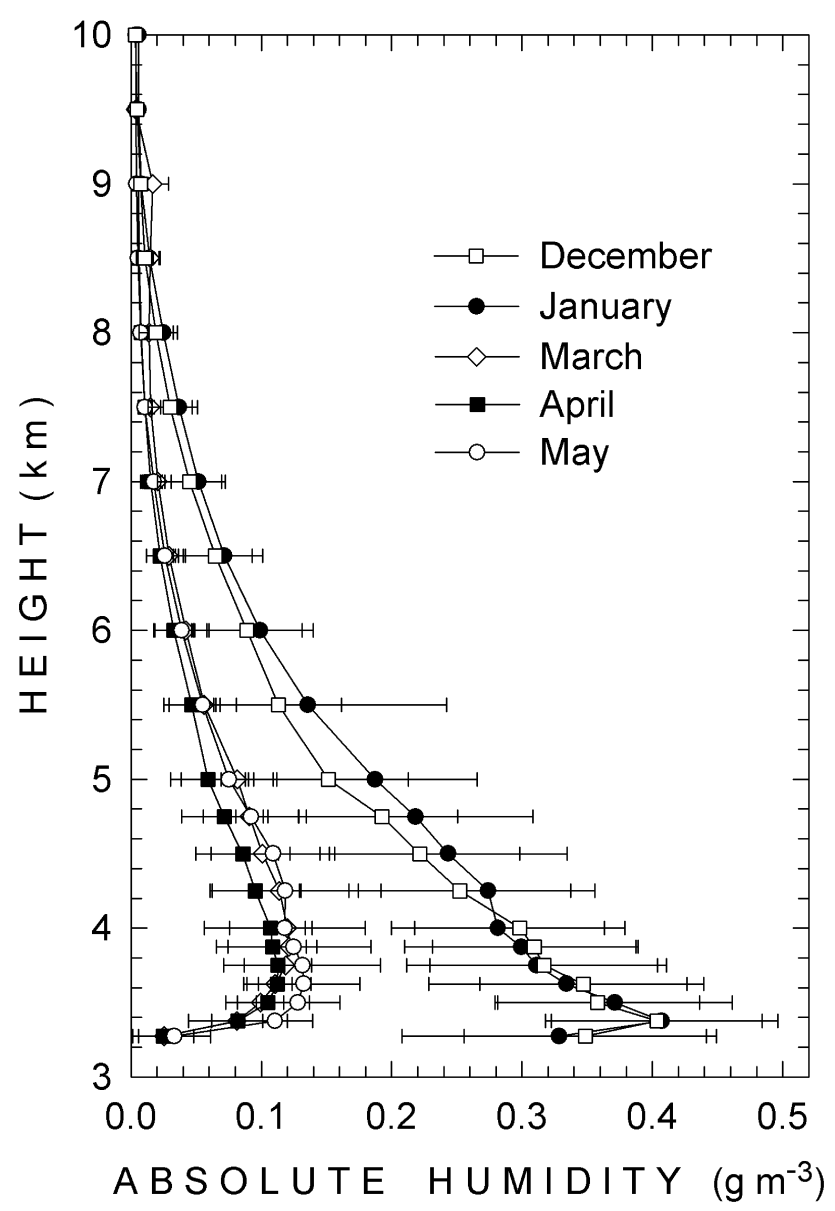

Figure 5. Mean monthly vertical profiles of absolute humidity $q\left(\mathrm{~g} \mathrm{~m}^{-3}\right)$ obtained from the monthly data sets of $q$ relative to December (open squares), January (solid circles), March (open diamonds), April (solid squares), and May (open circles). The bars represent the standard deviations obtained at some fixed levels, giving a measure of the dispersion of the monthly data. 


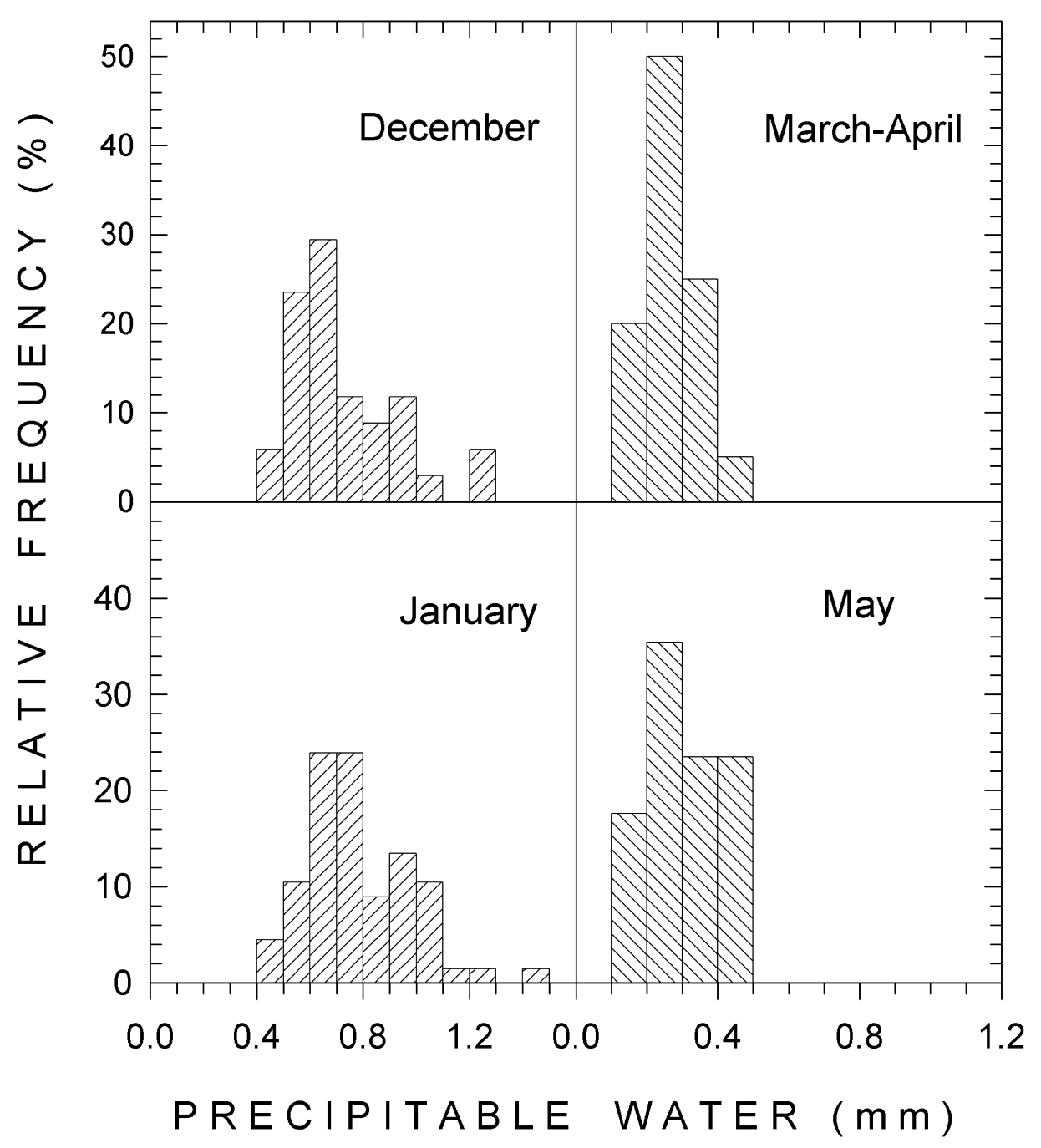

Figure 6. Comparison among the relative frequency histograms of precipitable water $W$ obtained for (left) the December and January data sets and (right) the March-April and May data sets.

The results indicate that there is a limited increase of the mean monthly value of $W$ from December to January and an appreciable increase from March/April to May. In order to better define the variations of $W$ during the above monthly periods and the dispersion features of this atmospheric parameter, Figure 6 presents the relative frequency histograms of $W$ drawn for the above four monthly subsets. The comparison between the December and January histograms indicates that both December and January data are characterized by bimodal features centered at about 0.65 and $0.95 \mathrm{~mm}$ in December and about 0.70 and $0.95 \mathrm{~mm}$ in January. Correspondingly, the quartiles of the relative frequency histograms were found to assume the values of $0.59,0.65$ and $0.89 \mathrm{~mm}$ in December and $0.65,0.74$ and $0.92 \mathrm{~mm}$ in January, presenting average increases smaller than $0.1 \mathrm{~mm}$ from the first month to the second. This shows that the moisture conditions of the troposphere observed above Dome $\mathrm{C}$ in December differ very little, on the average, from those measured in January.

[36] Comparing in Figure 6 the relative frequency histograms obtained for the March/April and May subsets, it can be seen that precipitable water $W$ measured on the last days of March and throughout April assumed very stable values, presenting limited discrepancies and giving form to a very narrow leptokurtic histogram covering the limited range from 0.1 to $0.5 \mathrm{~mm}$. Conversely, the results obtained in May were found to exhibit a frequency distribution curve of mesokurtic type within the same range of $W$. The curves were found to yield values of the quartiles equal to 0.21 , 0.24 and $0.32 \mathrm{~mm}$ in the March/April period, respectively, and to $0.23,0.26$ and $0.38 \mathrm{~mm}$ in May. Since the differences between the quartile values were relatively slight, the results confirm that only small variations in the moisture conditions of the atmosphere usually occur during these 2 months, while the atmosphere tends to become gradually colder and drier as the winter season approaches.

\section{Discussion of the Results}

[37] The relatively high values of the standard deviations of $W$ found in the various months and, more generally, the features of the relative frequency histograms presented in 


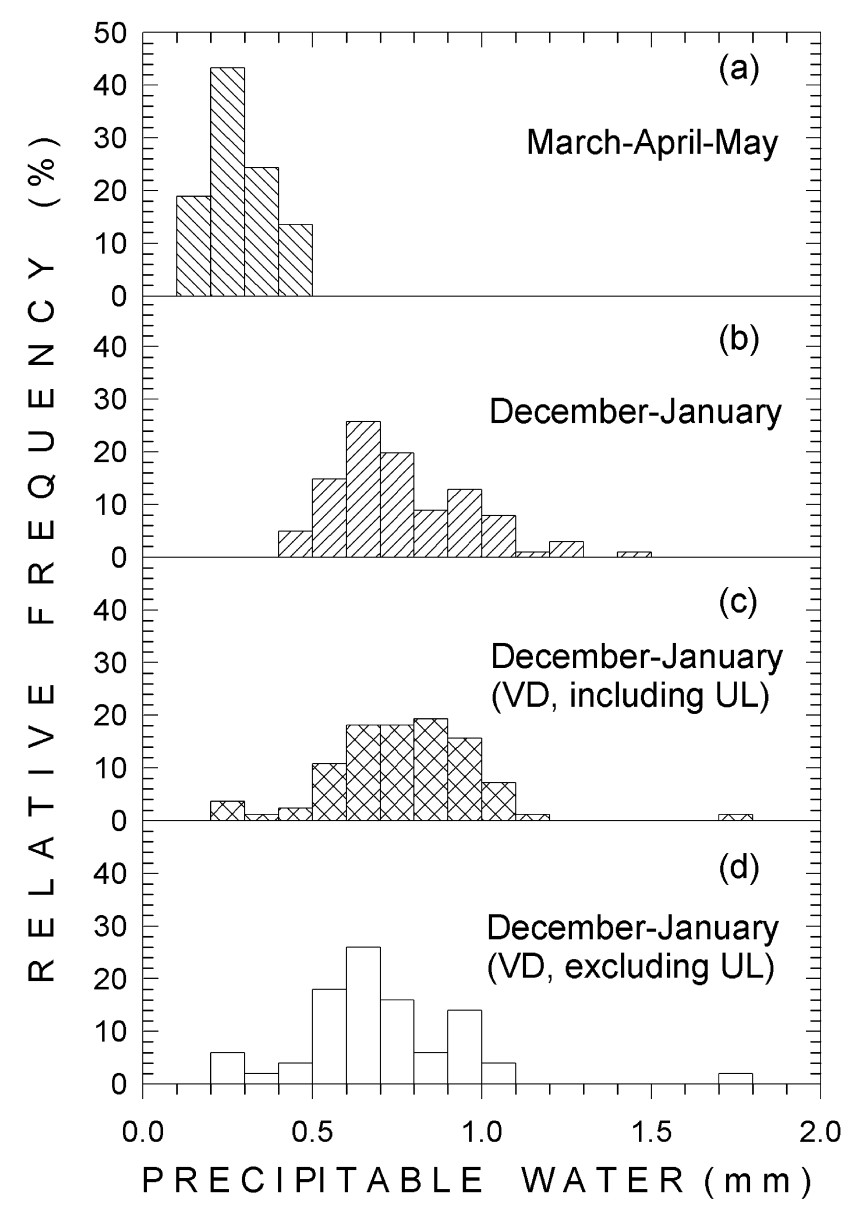

Figure 7. Comparison among the relative frequency histograms of precipitable water $W$ obtained for the following data sets: (a) the present March-April-May data set, (b) the present December-January data set, (c) the VD [Valenziano and Dall'Oglio, 1999] data set including the upper limit (UL) data, and (d) the VD data set excluding the UL data.

Figure 6, indicate that precipitable water assumes rather variable values in December and January and more stable values from late March to the end of May. In order to evaluate more precisely the measure of the changes in $W$ passing from the austral summer to fall season, it was decided to determine also the relative frequency histograms of $W$ for the two seasonal data sets. The first includes all the December/January data relative to 101 radiosoundings, and the latter all the March/April/May data relative to 37 radiosoundings in all. The calculation of the histograms shown in Figure 7 allows the definition of the quartiles, giving a measure of the large variations in the tropospheric moisture conditions that take place at Dome $\mathrm{C}$ passing from one period to the other. In fact, the two histograms are superimposed only within the limited range of $W$ from 0.4 to $0.5 \mathrm{~mm}$. The average values and the quartiles of $W$ found for the two seasonal data sets are reported in Table 2, showing an average percentage decrease of $62-65 \%$ of these parameters, when passing from the DecemberJanuary period to that from late March to the end of
May. The average values obtained for the two seasonal data sets were found to be $0.76 \mathrm{~mm}$ in December/January and $0.28 \mathrm{~mm}$ in March/April/May, indicating that a strong decrease of $W$ occurred on the average, by about $63 \%$ in relative units and by $0.48 \mathrm{~mm}$ in absolute units; this change is considerably greater than the sum of the corresponding standard deviations. The values of the quartiles given in Table 2 also confirm the general seasonal trend, since they decrease from 0.60 to $0.22 \mathrm{~mm}$, from 0.71 to $0.25 \mathrm{~mm}$, and from 0.90 to $0.34 \mathrm{~mm}$, respectively.

[38] The above relative frequency histograms are compared in Figure 7 with those determined by examining the original set of precipitable water data, the only one available to date for Dome C, measured by Valenziano and Dall'Oglio [1999] in December 1996 and January 1997. The data were collected using a modified "Volz-type" Sun photometer [Volz, 1974] to take regular measurements of direct solar irradiance throughout the day, within two nearby spectral channels of about $10 \mathrm{~nm}$ half bandwidth: the former was selected to have the transmission peak wavelength in the middle of the water vapor absorption band, commonly called $\rho \sigma \tau$, presenting its maximum absorption effects at around $0.94 \mu \mathrm{m}$; the latter was chosen with peak wavelength of about $0.87 \mu \mathrm{m}$, in the middle of the nearby atmospheric transparency window, free of significant water vapor absorption features. The ratio between the output voltages provided by the detector in the two channels within a few seconds gives a measure of the so-called hygrometric ratio $H$, which is strongly affected by water vapor absorption along the Sun path and hence is particularly sensitive to the time variations in the total water vapor mass distributed along the Sun path. This quantity is given by the product of precipitable water $W$ (measured along the vertical path) by the relative optical air mass $m$ for water vapor [Kasten, 1966; Tomasi et al., 1998].

[39] The instrument was calibrated at the Mario Zucchelli station (formerly called Terra Nova Bay (TNB)) before being employed at Dome $\mathrm{C}$, using the values of $W$ directly determined from the original radiosoundings data taken there. The Valenziano and Dall'Oglio [1999] data set is composed of (1) a first set of values of $W$ collected within the dynamic range of the instrument, both in the transparency and in the absorption band, which was found to consist of an overall number of 50 values and is referred to in Table 2 as the "VD data set excluding UL," and (2) an enlarged set, containing the previous 50 values of $W$ and 33 additional measurements, which is referred to in Table 2 as the "VD data set including UL." In the above definitions, the acronym UL is adopted to indicate the "upper limits" reached by the instrument in all cases where the absorption band readings turn out to be close to the instrument dynamic range, as a result of very high transmission features of solar radiation through the polar atmosphere. Therefore the real water vapor content at that time could only have been lower than the measured UL value.

[40] The comparison shown in Figure 7 between the present December/January histogram and those obtained for both VD data sets clearly indicates that the range of $W$ found for the present results is appreciably shifted toward the right with respect to the VD intervals. This discrepancy is presumably due to the fact that the VD data sets were originally obtained using three approximations: (1) calibra- 
Table 2. Comparison Among the Mean Values of Precipitable Water $W$ and the Corresponding Quartile Values Found From the Present Dome C Data Sets, the Dome C Data Sets of Valenziano and Dall'Oglio [1999], and the South Pole Findings of Chamberlin et al. [1997] Relative to the Austral Winter/Spring (From April to September of 1995) and Summer (From January to March and From October to December of 1995) Periods ${ }^{\mathrm{a}}$

\begin{tabular}{|c|c|c|c|c|c|}
\hline \multirow[b]{2}{*}{ Measurement Site } & \multirow[b]{2}{*}{ Measurement Period } & \multicolumn{4}{|c|}{ Values of Precipitable Water $W, \mathrm{~mm}$} \\
\hline & & Mean & First Quartile & Median & Third Quartile \\
\hline Dome C (present results) & December-January 2003/2004 & $0.76 \pm 0.20$ & 0.60 & 0.71 & 0.90 \\
\hline Dome C (present results) & March-April-May 2005 & $0.28 \pm 0.09$ & 0.22 & 0.25 & 0.34 \\
\hline Dome C (VD data, excluding UL) & December-January 1996/1997 & $0.72 \pm 0.56$ & 0.38 & 0.52 & 0.68 \\
\hline Dome C (VD data, including UL) & December-January, 1996/1997 & $0.76 \pm 0.44$ & 0.47 & 0.64 & 0.78 \\
\hline South Pole [Chamberlin et al., 1997] & Austral summer 1995/1996 & - & 0.43 & 0.54 & 0.72 \\
\hline South Pole [Chamberlin et al., 1997] & Austral winter/spring 1995 & - & 0.19 & 0.25 & 0.32 \\
\hline Mauna Kea [Hogg, 1992] & January-June 1989/1990/1991 & - & 1.05 & 1.65 & 3.15 \\
\hline Mauna Kea [Hogg, 1992] & July-December 1990/1991 & - & 1.73 & 2.98 & 5.88 \\
\hline Atacama [Lane, 1998] & April-September, 1995 & - & 0.68 & 1.00 & 1.60 \\
\hline Atacama [Lane, 1998] & October 1995 to March 1996 & - & 1.10 & 2.00 & 3.70 \\
\hline Atacama [Giovanelli et al., 2001] & October 1998 to August 2000 & - & 0.71 & 1.04 & 1.75 \\
\hline
\end{tabular}

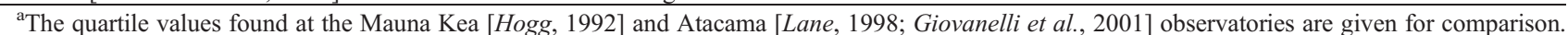
The monthly mean values of $W$ measured at the Kitt Peak National Observatory (USA) were found by Wallace and Livingston [1984] to assume a minimum of 3-4 mm during December through March and a maximum of about $27 \mathrm{~mm}$ in August. VD refers to Valenziano and Dall'Oglio [1999].

tion used RH measurements provided by the RS80-A radiosondes, which were not corrected for the dry bias, due to the poor knowledge of the problem related to the occurrence of dry bias at that time, before the publication of W02 and M04 results, (2) no correction was applied for actual surface pressure conditions at Dome $\mathrm{C}$ during the observation period, and (3) the square root law was used to define the calibration curve of hygrometric ratio, which is not accurate for low atmospheric water vapor contents [Goody, 1964; Volz, 1983; Tomasi et al., 1990]. The first two approximations induce an underestimation of $W$, while the last one generates a partially compensating overestimation.

[41] Table 2 also shows the quartiles of $W$ determined by Chamberlin et al. [1997] at South Pole for two data sets including precipitable water measurements carried out during the austral winter-spring months of 1995 and the austral summer from October 1995 to March 1996. The comparison shows a close agreement between the present Dome C results found from late March to the end of May and those determined by Chamberlin et al. [1997] in the austral winter/spring period. The latter provide the same median values, with relative differences of $14 \%$ between the first quartiles and less than $6 \%$ between the third quartiles. This agreement can be explained by the very cold thermal conditions of the troposphere usually encountered at the two sites during the winter season: the surface temperature at South Pole varies between $191 \mathrm{~K}$ and $224 \mathrm{~K}$ from April to September and that at Dome $\mathrm{C}$ between $201 \mathrm{~K}$ and $233 \mathrm{~K}$ in March, April and May. Discrepancies of 20-40\% were instead found between the quartile values of $W$ determined by Chamberlin et al. [1997] at South Pole in the austral summer, and those found at Dome C in December 2003 and January 2003/2004. These differences are presumably due in part to the warmer air conditions observed at Dome $\mathrm{C}$ during the two local summer months compared to those measured at South Pole throughout the 6 month period, referred to as austral summer 1995/1996 in Table 2.

\section{Conclusions}

[42] The results confirm that the water vapor content of the atmosphere above Dome $\mathrm{C}$ assumes very low values throughout the year, which are closely comparable with those measured at South Pole during the austral winter. Appreciably higher values of $W$ were found in December and January at Dome $\mathrm{C}$ than those measured by Chamberlin et al. [1997] at South Pole throughout the whole austral summer period, presenting a relative difference of $24 \%$ between the corresponding median values. Such discrepancies can be ascribed at least in part to the fact that precipitable water was measured at Dome $\mathrm{C}$ for the warmest austral summer 2 month period instead of the 6 month period from October to March at South Pole.

[43] On the basis of field experiments conducted at Dome $\mathrm{C}$ for radiometric validation of the Atmospheric Infrared Sounder (AIRS) during the same austral summer period (January 2003/04 and December 2003) considered in the present analysis, Walden et al. [2006] found that Dome C is a good site also for validation of satellite radiance measurements and water vapor retrievals, due to the low precipitable water values.

[44] The low contents of atmospheric water vapor found in this paper (see Table 2 for a comparison with other wellestablished sites) confirm that the high Antarctic Plateau is one of the driest site on Earth, presenting exceptional transparency conditions at infrared, submillimetric and millimetric wavelengths. When comparing the global site quality for astronomical observation between Dome $\mathrm{C}$ and South Pole, other parameters need to be considered. Dome $\mathrm{C}$ presents lower ground temperatures (i.e., lower telescope emissivity in the infrared), lower wind speeds and lower boundary layer turbulence, as illustrated by Valenziano and Dall'Oglio [1999], Lawrence et al. [2004], and Lawrence [2004]. Moreover, observations in the far-infrared range (i.e., 40-300 $\mu \mathrm{m}$ ) can only be performed with groundbased instruments in exceptionally dry air conditions, which are sporadically present at Chilean sites [Giovanelli et al., 2001] but quite common in the Antarctic ones. A definitive comparison in terms of site quality for astronomy between South Pole and Dome $\mathrm{C}$ requires more data from the latter site. However, the present results and those available in the literature candidate Dome $\mathrm{C}$ to be superior in absolute terms. This advantage may represent a key point when projects for extremely large telescopes (diameter above 
$10 \mathrm{~m}$ that cannot be carried on satellites) are concerned: even a small advantage in transparency or integration time may constitute a critical issue in site selection. Furthermore, due to the harsh operating conditions, similar in some respects to those encountered in space, Dome $\mathrm{C}$ could also be used as a test bench for future activities on the Moon and on other extraterrestrial bodies.

[45] Acknowledgments. This research was supported by the Programma Nazionale di Ricerche in Antartide (PNRA) and developed as a part of subproject 2005/6.2 "POLAR-AOD: a network to characterize the means, variability and trends of the climate-forcing properties of aerosols in polar regions." The authors gratefully acknowledge the International Center for Theoretical Physics (ICTP, Trieste, Italy) for its support of the participation of B. Petkov, in the frame of the "Programme for Training and Research in Italian Laboratories."

\section{References}

Aristidi, E., A. Agabi, J. Vernin, M. Azouit, F. Martin, A. Ziad, and E. Fossat (2003), Antarctic site testing: First daytime seeing monitoring at Dome C, Astron. Astrophys., 406, L19-L22.

Aristidi, E., et al. (2005), An analysis of temperatures and wind speeds above Dome C, Antarctica, Astron. Astrophys., 430, 739-746.

Bally, J. (1989), Atmospheric transparency over Antarctica from the midinfrared to centimeter wavelengths, in Astrophysics in Antarctica, edited by D. J. Mullan, M. A. Pomerantz, and T. Stanev, pp. 100-105, AIP Press, New York.

Bignell, K. J. (1970), The water-vapor infrared continuum, Q. J. R. Meteorol. Soc., 96, 390-403.

Bolton, D. (1980), The computation of equivalent potential temperature, Mon. Weather Rev., 108, 1046-1053.

Burton, M. G., D. K. Aitken, D. A. Allen, M. C. B. Ashley, R. D. Cannon, B. D. Carter, G. S. Dacosta, M. A. Dopita, and M. L. Duldig (1994), The scientific potential for astronomy from the Antarctic Plateau, Publ. Astron. Soc. Aust., 11, 127-150.

Bussmann, R. S., W. L. Holzapfel, and C. L. Kuo (2005), Millimeter wavelength brightness fluctuations of the atmosphere above the South Pole, Astrophys. J., 622, 1343-1355.

Calisse, P. G., M. C. B. Ashley, M. G. Burton, M. A. Phillips, J. W. V. Storey, S. J. E. Radford, and J. B. Peterson (2004), Submillimeter site testing at Dome C, Antarctica, Publ. Astron. Soc. Aust., 21, 1-18.

Chamberlin, R. A., A. P. Lane, and A. A. Stark (1997), The $492 \mathrm{GHz}$ atmospheric opacity at the geographic South Pole, Astrophys. J., 476, $428-433$.

Clough, S. A., F. X. Kneizys, and R. W. Davies (1989), Line shape and the water vapor continuum, Atmos. Res., 23, 229-241.

Giovanelli, R., et al. (2001), The optical/infrared astronomical quality of High Atacama sites. II. Infrared characteristics, Publ. Astron. Soc. Pac., $113,803-813$.

Goody, R. M. (1964), Atmospheric Radiation, I.- Theoretical Basis, pp. 67-232, Clarendon Press, Oxford, U. K.

Hogg, D. E. (1992), A summary of the data obtained during the MMA site survey, Millimeter Array Memo. 79, Natl. Radio Obs., Charlottesville, Va.

Huovila, S., and A. Tuominen (1991), Influence of radiosonde lag errors on upper-air climatological data, paper presented at Seventh Symposium on Meteorological Observations and Instrumentation, Special Sessions on Laser Atmospheric Studies, Am. Meteorol. Soc., New Orleans, La., 14-18 Jan.

Kasten, F. (1966), A new table and approximation formula for the relative optical air mass, Arch. Meteorol. Geophys. Biokl., Ser. B, 14(2), 206223.

Kondratyev, K. Y. (1969), Radiation in the Atmosphere, pp. 85-159, Elsevier, New York.

Lane, A. P. (1998), Submillimeter transmission at South Pole, in Astrophysics From Antarctica, ASP Conf. Ser., vol. 141, edited by G. Novak and R. H. Landsberg, pp. 289-295, Astron. Soc. of the Pac., San Francisco, Calif.

Lawrence, J. S. (2004), Infrared and submillimeter atmospheric characteristics of High Antarctic Plateau Sites, Publ. Astron. Soc. Pac., 116, 482492.

Lawrence, J. S., M. C. B. Ashley, A. Tokovinin, and T. Travouillon (2004), Exceptional astronomical seeing conditions above Dome C in Antarctica, Nature, 431, 278-281.

Leckner, B. (1978), The spectral distribution of solar radiation at the Earth's surface - Elements of a model, Sol. Energy, 20, 143-150.

Leiterer, U., H. Dier, D. Nagel, T. Naebert, D. Althausen, K. Franke, and F. Wagner (2005), Correction method for RS80-A Humicap humidity profiles and their validation by lidar backscattering profiles in tropical cirrus clouds, J. Atmos. Oceanic Technol., 22, 18-29.

Luers, J. K. (1997), Temperature error of the Vaisala RS90 radiosonde, J. Atmos. Oceanic Technol., 14, 1520-1532.

Luers, J. K., and R. E. Eskridge (1995), Temperature corrections for the VIZ and Vaisala radiosondes, J. Appl. Meteorol., 34, 1241-1253.

Marsden, D., and F. P. J. Valero (2004), Observation of water vapour greenhouse absorption over the Gulf of Mexico using aircraft and satellite data, J. Atmos. Sci., 61, 745-753.

Miloshevich, L. M., H. Vömel, A. Paukkunen, A. J. Heymsfield, and S. J. Oltmans (2001), Characterization and correction of relative humidity measurements from Vaisala RS80-A radiosondes at cold temperatures, J. Atmos. Oceanic Technol., 18, 135-156.

Miloshevich, L. M., A. Paukkunen, H. Vömel, and S. J. Oltmans (2004), Development and validation of a time-lag correction for Vaisala radiosonde humidity measurements, J. Atmos. Oceanic Technol., 21, 1305-1327.

Miloshevich, L. M., H. Vömel, D. N. Whiteman, B. M. Lesht, F. J. Schmidlin, and F. Russo (2006), Absolute accuracy of water vapour measurements from six operational radiosonde types launched during AWEX-G and implications for AIRS validation, J. Geophys. Res., 111, D09S10, doi:10.1029/2005JD006083.

Tomasi, C., V. Vitale, M. Tagliazucca, and L. Gasperoni (1990), Infrared hygrometry measurements at Terra Nova Bay, in Second Workshop Italian Research on Antarctic Atmosphere, SIF Conf. Proceed., vol. 27, edited by M. Colacino, G. Giovanelli, and L. Stefanutti, pp. 187-200, Editrice Compositori, Bologna, Italy.

Tomasi, C., V. Vitale, and L. V. De Santis (1998), Relative optical mass functions of air, water vapor, ozone and nitrogen dioxide in atmospheric models presenting different latitudes and seasonal conditions, Meteorol. Atmos. Phys., 65, 11-30.

Tomasi, C., A. Cacciari, V. Vitale, A. Lupi, C. Lanconelli, A. Pellegrini, and P. Grigioni (2004), Mean vertical profiles of temperature and absolute humidity from a twelve-year radiosounding data-set at Terra Nova Bay (Antarctica), Atmos. Res., 71, 139-169.

Turner, D. D., B. M. Lesht, S. A. Clough, J. C. Liljegren, H. E. Revercomb, and D. C. Tobin (2003), Dry bias and variability in Valsala RS80-H radiosondes: The ARM experience, J. Atmos. Oceanic Technol., 20, $117-132$.

Valenziano, L., and G. Dall'Oglio (1999), Millimetre astronomy from the high Antarctic Plateau: Site testing at Dome C, Publ. Astron. Soc. Aust., $16,167-174$

Valenziano, L., et al. (1998), APACHE96. CMBR anisotropy experiment at Dome C, in Astrophysics From Antarctica, edited by G. Novak and R. H. Landsberg, pp. 81-89, Astron. Soc. of the Pac., San Francisco, Calif.

Volz, F. E. (1974), Economical multispectral sun-photometer for measurements of aerosol extinction from $0.44 \mu \mathrm{m}$ to $1.6 \mu \mathrm{m}$ and precipitable water, Appl. Opt., 13, 1732-1734

Volz, F. E. (1983), Comments on "Precipitable water measurements with sun-photometers", J. Clim. Appl. Meteorol., 22, 1967-1968.

Walden, V. P., W. L. Roth, R. S. Stone, and B. Halter (2006), Radiometric validation of the Atmospheric Infrared Sounder over the Antarctic Plateau, J. Geophys. Res., 111, D09S03, doi:10.1029/2005JD006357.

Wallace, L., and W. Livingston (1984), Characteristics of water vapour over Kitt Peak, Publ. Astron. Soc. Pac., 96, 182-186.

Wang, J., H. L. Cole, D. J. Carlson, E. R. Miller, K. Beierle, A. Paukkunen, and T. K. Laine (2002), Corrections of humidity measurement errors from the Vaisala RS80 radiosonde: Application to TOGA COARE data, J. Atmos. Oceanic Technol., 19, 981-1002.

Waters, J. W. (1976), Atmospheric effects, in Methods of Experimental Physics: Astrophysics, Part B, Radio Telescopes, edited by M. L. Meeks, pp. $142-146$, Elsevier, New York.

Yamanouchi, T., and T. O. Charlok (1995), Comparison of radiation budget at TOA and surface in the Antarctica from ERBE and ground surface measurements, J. Clim., 8, 3109-3120.

E. Benedetti, B. Petkov, C. Tomasi, and V. Vitale, ISAC, CNR, via Gobetti 101, I-40129 Bologna, Italy. (c.tomasi@isac.cnr.it)

G. Dargaud and A. Pellegrini, Antarctic Project, Centro Ricerche Casaccia, ENEA, via Anguillarese 301, I-00060 Santa Maria di Galeria, Rome, Italy.

L. De Silvestri and P. Grigioni, Climate Section, Centro Ricerche Casaccia, ENEA, via Anguillarese 301, I-00060 Santa Maria di Galeria, Rome, Italy.

E. Fossat, Laboratoire d'Astrophysique, Université de Nice SophiaAntipolis, F-06108 Nice Cedex 02, France.

W. L. Roth, Department of Geography, University of Idaho, Moscow, ID 83844-3021, USA.

L. Valenziano, Institute of Space Astrophysics and Cosmic Physics, INAF, via Gobetti 101, I-40129 Bologna, Italy. 